\title{
Mineração
}

\section{Comportamento geotécnico de rochas brandas na mina Córrego do Sítio, Santa Bárbara (MG)}

\section{(Geotechnical behavior of weak rocks in Córrego do Sítio mine, Santa Bárbara (MG))}

\author{
Manoel da Conceição Lopes \\ Mestreem Engenharia Mineral,DEMIN/UFOP.E-mail:manoellopes@uai.com.br \\ Milene Sabino Lana \\ Professora Adjunta da Escola de Minas, DEMIN/UFOP.E-mail: milene@demin.ufop.br \\ Luis Fernando Martins Ribeiro \\ Professor Adjunto da Universidade de Brasília, UNB. E-mail: Imartins@unb.br \\ Carolina Helena Caldeira Silva \\ Mestranda em Engenharia Ambiental, UFOP.E-mail: carolina@aluno.ambiental.ufop.br
}

\section{Resumo}

Nesse trabalho, é discutida a caracterização de filitos na Mina Córrego do Sítio, em Santa Bárbara-MG, bem como determinados fatores que influenciam a resistência ao cisalhamento da xistosidade. São apresentados e discutidos resultados de caracterização mineralógica, índices físicos e de ensaios de cisalhamento direto em três áreas dessa Mina. O intemperismo atua na variação de determinadas propriedades, tais como porosidade, índice de vazios, peso específico seco e, também, na resistência mecânica, com queda acentuada de coesão após ensaio de alterabilidade. Por outro lado, a acentuada rugosidade presente na superfície de xistosidade das rochas da Cava Crista influencia no comportamento do maciço rochoso, conferindo-lhe maior resistência ao cisalhamento.

Palavras-chave: Rochas brandas, alterabilidade, resistência ao cisalhamento.

\begin{abstract}
In this work the characterization of phyllites in the Córrego do Sítio Mine, Santa Bárbara, MG, is discussed, as well as some factors that influence the shear strength along the foliation surface. Results of mineralogic description, physical indices and direct shear tests of three areas in this mine are presented. Weathering acts on the variability of some properties, such as the porosity, void ratio, dry specific gravity, and also on the shear strength, with considerable reduction of the cohesion after alterability tests. In addition, the roughness observed on the foliation surface in the rocks of Crista pit influences the rock mass behaviour, increasing its shear strength.
\end{abstract}

Keywords: Weak rocks, alterability, shear strength. 


\section{Introdução}

Embora exista uma grande variedade de rochas brandas no Brasil, pouco se conhece sobre seu comportamento geotécnico. Grande parte dos dados disponíveis refere-se a rochas sãs ou pouco alteradas.

Na região do Quadrilátero Ferrífero, embora muito investigada em termos geológicos, ainda há grande carência de dados geotécnicos envolvendo suas rochas brandas.

Essa carência de informações referentes a essas rochas deve-se, muitas vezes, a dificuldades na amostragem e preparação de corpos-de-prova para a realização de ensaios mecânicos. A heterogeneidade apresentada por essas rochas também contribui para a carência de dados de propriedades físicas e mecânicas. Também a falta de uma metodologia adequada aplicável à caracterização geotécnica de rochas alteradas, por serem de baixa resistência, é outro fator que compromete a determinação da resistência mecânica.

Nesse trabalho, será dada ênfase ao estudo do comportamento geotécnico das rochas presentes na Mina Córrego do Sítio do Grupo Anglo Gold Ashanti, situada a aproximadamente $20 \mathrm{~km}$ do município de Santa Bárbara/MG, as quais são constituídas por filitos associados a metagrauvaca. A ocorrência de dobramentos, fraturamento acentuado em algumas áreas e o clima tropical úmido conduziram à formação de rochas de muito baixa resistência, cuja caracterização geotécnica é dificultada pela dificuldade de aplicação da metodologia tradicional para caracterização geotécnica de rochas.

Os índices físicos e a resistência ao cisalhamento dos filitos presentes nas Cavas Crista, Cristina e Cachorro Bravo são determinados e os resultados discutidos. As diferenças de comportamento dos filitos explicam as diferentes condições de estabilidade observadas nas Cavas Crista e Cachorro Bravo.
2. Material e métodos

\subsection{Caracterização da área- Mina Córrego do Sítio}

A Mina Córrego do Sítio, pertencente ao Grupo Anglo Gold Ashanti, constituída por frentes de lavra de minério de ouro oxidado, situa-se a aproximadamente 20 km da cidade de Santa Bárbara/MG. Seu acesso é feito através da MG-436 e localiza-se a aproximadamente 120 km de Belo Horizonte.

A região está inserida na porção nordeste do Quadrilátero Ferrífero e é drenada pela bacia do Rio Doce. O córrego do Sítio é afluente da margem esquerda do córrego Caraça, o qual é afluente da margem direita do rio Conceição.

As rochas da Mina Córrego do Sítio, pertencentes ao Grupo Nova Lima, Supergrupo Rio das Velhas, ocorrem em uma seqüência vulcanossedimentar arqueana tipo greenstone belt.

Predominam, basicamente, filitos cloríticos, localmente quartzosos ou sericíticos, com níveis carbonosos, associados a xistos quartzo-micáceos, às vezes caulínicos. Como resultado da alteração hidrotermal, tem-se a presença de zonas de sericitação e carbonatação nessas rochas.

O presente estudo enfocou as Cavas Crista, Cristina e Cachorro Bravo. Com relação a essas áreas, ressalta-se:

- Cava Crista - o material dessa cava apresenta intensa silicificação, carbonatação, seritização e sulfetação. De acordo com estudos anteriores, o material é classificado, segundo a ISRM (1981), em R3/W3, em relação à resistência/alteração, denotando um maciço rochoso de boa qualidade geomecânica.

- Cava Cristina - encontra-se na zona de contato de filitos/xistos carbonosos com filitos/xistos sericíticos mais ou menos quartzosos. As rochas apresentam resistência/alteração de R3/ W3(ISRM, 1981).
- Cava Cachorro Bravo: esta área é constituída por filitos com a presença de quartzo, sericita, carbonato oxidado e sulfetos limonitizados e dique básico constituído de carbonato e anfibólio. As rochas apresentam resistência/alteração, segundo a ISRM (1981), R2/W4, denotando um maciço rochoso de baixa qualidade geomecânica.

\subsection{Caracterização mineralógica}

Marques e Vargas Jr (1994) salientam a importância da caracterização mineralógica na identificação de argilo-minerais e qualquer outra substância que possa causar expansão ou contração da rocha.

Os componentes mineralógicos foram identificados a partir de ensaios de difratometria de raios $\mathrm{X}$ e de análise petrográfica por lâminas delgadas, no intuito de prever o comportamento do material perante fatores externos e de identificar as principais características que influenciam seu comportamento geomecânico.

As análises mineralógicas foram realizadas no laboratório de RX e de microscopia óptica do DEGEO/UFOP.

\section{3 Índices Físicos}

As propriedades das rochas medidas em laboratório auxiliam na sua caracterização e classificação.

Foram determinados os seguintes índices físicos das rochas:

- Massa específica dos grãos $\mathrm{G}_{\mathrm{s}}$ (ABNT NBR 6508, 1984).

- Peso específico natural $(\gamma)$.

- Peso específico seco $\left(\gamma_{d}\right)$.

- Índice de vazios (e).

- Porosidade (n).

Esses índices físicos foram determinados antes e após o ensaio de alterabilidade (ciclagem água-estufa). O ensaio de alterabilidade consistiu em submeter 
as amostras a ciclos alternados de umedecimento e secagem, com o objetivo de simular o efeito do intemperismo no material (CESP, 1990).

\subsection{Ensaio de cisalhamento direto}

Para a determinação dos parâmetros de resistência (c - coesão e $\phi$ - ângulo de atrito), foram realizados ensaios de cisalhamento direto para amostras no estado natural, com aplicação de esforço tangencial paralelo à superfície de xistosidade.

Devido ao grau de alteração apresentado pelas amostras, os procedimentos adotados para ensaios de cisalhamento direto em corpos rochosos não puderam ser aplicados. Diante da dificuldade de moldagem dos corpos-deprova nas condições exigidas para ensaios em rocha, foram adotados os procedimentos para ensaios de cisalhamento direto em amostras de solo. Fernandes (2000) adotou os mesmos procedimentos para a realização dos ensaios de cisalhamento direto em amostras de xistos do Morro do Curral, Ouro Preto-MG.

Nos ensaios, foram utilizadas tensões normais de 50, 100, 200 e $400 \mathrm{kPa}$, para as amostras das Cavas Cachorro Bravo e Cristina. E, para os corpos-deprova da Cava Crista, adotaram-se tensões de 25, 50, 100, 200, 300 e 400 kPa. Esse maior número de tensões normais foi adotado porque, para essa última área, efetuou-se um ajuste não linear (curvilíneo), para determinar a envoltória de resistência, sendo necessário executar um maior número de ensaios para que esse ajuste pudesse ser feito. No caso das duas primeiras áreas, adotou-se o ajuste linear, estabelecido pelo critério de Mohr-Coulomb.

Os corpos-de-prova foram moldados com auxílio de uma serra diamantada, com dimensões aproximadas de 10x10x2cm. Eles foram confeccionados no Laboratório de Laminação do Departamento de Geologia-DEGEO e na Oficina de Cantaria-DEMIN. Os ensaios foram realizados no Laboratório de Geotecnia-UFOP.

\section{Resultados e discussão}

\subsection{Caracterização Mineralógica}

Os resultados dos ensaios de difração de RX identificaram a presença de quartzo, muscovita e caulinita em todas as amostras. Na análise, a partir de lâminas delgadas, observou-se, em todas as rochas analisadas, que o quartzo é o mineral constituinte principal. Ele ocorre incolor, em cristais com hábito granular e, também, alongado segundo a foliação, seguido da presença de sericita e muscovita. Ferreira (2004) encontrou resultados semelhantes para o xisto estudado no Morro do Curral, em Ouro Preto-MG. Watters (1997) comenta que a caulinita é o mais comum produto de alteração tropical.

Interessante destacar a presença de clivagem de crenulação (foliação gerada sobre rocha metamórfica, normalmente rica em filossilicatos, micas, em decorrência de microdobras), na lâmina da Cava Crista. (Figura 1).

\section{2 Índices Físicos}

Os resultados referentes aos índices físicos são apresentados na Tabela 1.

Verifica-se, pela Tabela 1, que houve variações nos índices físicos com o ensaio de alterabilidade. Pode-se dizer que um aumento na porosidade e uma redução no peso específico seco são indicadores do processo de alteração, reflexo da velocidade de alteração no tempo. $\mathrm{O}$ aumento na porosidade favorece a percolação de água na rocha e, conseqüentemente, a sua desintegração.

A pequena variação nesses índices deve-se ao pequeno número de ciclos de umedecimento e secagem experimentados pelas amostras. Não foi possível a realização de um número maior de ciclos devido à desintegração da maioria das amostras durante a realização do ensaio de alterabilidade.

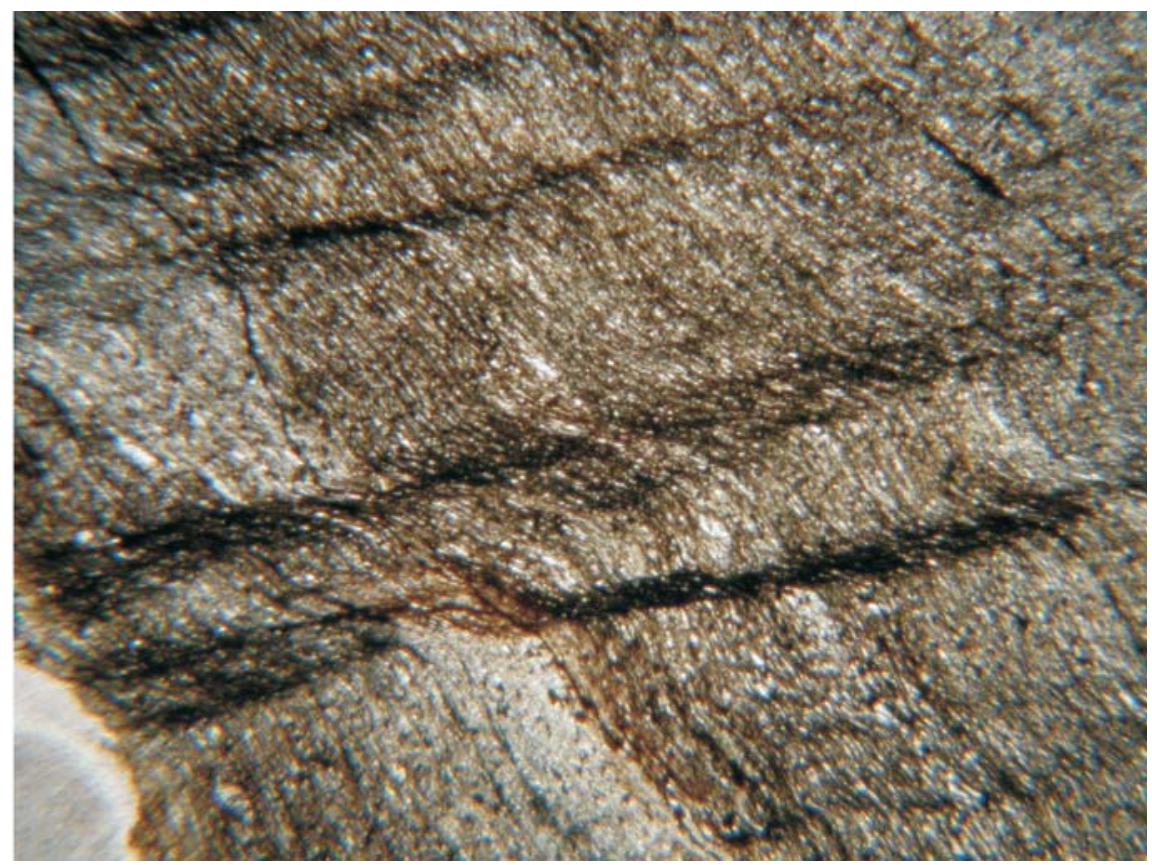

Figura 1 - Clivagem de crenulação (Cava Crista). 


\subsection{Ensaio de resistência ao cisalhamento}

\subsubsection{Cava Crista}

As amostras da Cava Crista são caracterizadas pela presença de rugosidade na superfície de xistosidade, o que acaba por aumentar a sua resistência.

A rugosidade em superfícies de juntas naturais tem uma influência significativa no seu comportamento. As superfícies rugosas, geralmente, aumentam a resistência ao cisalhamento e esse aumento é, extremamente, importante, em termos de estabilidade do maciço. Devido à presença de rugosidade nas amostras dessa área, os resultados obtidos ajustaram-se melhor a uma envoltória de resistência curvilínea.

Para a Cava Crista, adotou-se uma curva de potência com a seguinte equação: $\boldsymbol{\tau}=\mathbf{a}\left(\mathbf{s}_{\mathbf{n}}\right)^{\mathbf{b}}$, onde a $=172,01 \mathrm{e}$ $\mathrm{b}=0,2357$, ou seja, $\tau=172,01 \sigma^{0,2357}$ (Figura 2).

Os parâmetros equivalentes de Mohr-Coulomb, considerando-se a altura da bancada da Cava Crista de $15 \mathrm{~m}$, foram determinados: coesão de 395,53 kPa e ângulo de atrito igual a $40^{\circ}$.

\subsubsection{Cava Cristina}

Os resultados do ensaio de cisalhamento direto das amostras da Cava Cristina mostraram coesão de 126,97 kPa e ângulo de atrito de $45,5^{\circ}$ e coesão de $91,32 \mathrm{kPa}$ e ângulo de atrito de $43,5^{\circ}$ após ciclagem. Observa-se significativa queda da coesão após a realização dos ensaios de alterabilidade (Figuras 3a e 3b, respectivamente), resultante da perda de material de preenchimento, afetando, drasticamente, a resistência ao cisalhamento na superfície de xistosidade.

\subsubsection{Cava Cachorro Bravo}

Para essa área, obteveram-se coesão de 158,94 kPa e ângulo de atrito de $33,77^{\circ}$ (Figura 4). Figueiredo e Aquino (2005) adotaram um ângulo de atrito de $32,2^{\circ}$, para o filito sericítico da MBR (Minerações Brasileiras Reunidas), o qual
Tabela 1 - Índices físicos das Cavas Crista, Cristina e Cachorro Bravo.

\begin{tabular}{|c|c|c|}
\hline Áreas & $\begin{array}{c}\text { Amostras antes do } \\
\text { ensaio de } \\
\text { alterabilidade }\end{array}$ & $\begin{array}{c}\text { Amostras após o } \\
\text { ensaio de } \\
\text { alterabilidade }\end{array}$ \\
\hline Cava Crista & $\begin{array}{c}\mathrm{Gs}=2,78 \\
\gamma=2,29 \mathrm{~g} / \mathrm{cm}^{3} \\
\gamma_{d}=2,21 \mathrm{~g} / \mathrm{cm}^{3} \\
\mathrm{n}=20,50 \% \\
e=0,26\end{array}$ & $\begin{array}{c}\mathrm{Gs}=2,78 \\
\gamma_{d}=2,18 \mathrm{~g} / \mathrm{cm}^{3} \\
\mathrm{n}=21,58 \% \\
\mathrm{e}=0,28\end{array}$ \\
\hline Cava Cachorro Bravo & $\begin{array}{c}\mathrm{Gs}=2,75 \\
\gamma=2,00 \mathrm{~g} / \mathrm{cm}^{3} \\
\gamma_{d}=1,90 \mathrm{~g} / \mathrm{cm}^{3} \\
\mathrm{n}=30,90 \% \\
e=0,44\end{array}$ & $\begin{array}{c}\text { Gs }=2,75 \\
\gamma_{d}=1,80 \mathrm{~g} / \mathrm{cm}^{3} \\
\mathrm{n}=34,54 \% \\
\mathrm{e}=0,52\end{array}$ \\
\hline Cava Cristina & $\begin{array}{c}\text { Gs }=2,71 \\
\gamma=2,01 \mathrm{~g} / \mathrm{cm}^{3} \\
\gamma_{d}=1,96 \mathrm{~g} / \mathrm{cm}^{3} \\
\mathrm{n}=27,67 \% \\
e=0,38\end{array}$ & $\begin{array}{c}G s=2,71 \\
\gamma_{d}=1,93 \mathrm{~g} / \mathrm{cm}^{3} \\
n=28,78 \% \\
e=0,40\end{array}$ \\
\hline
\end{tabular}

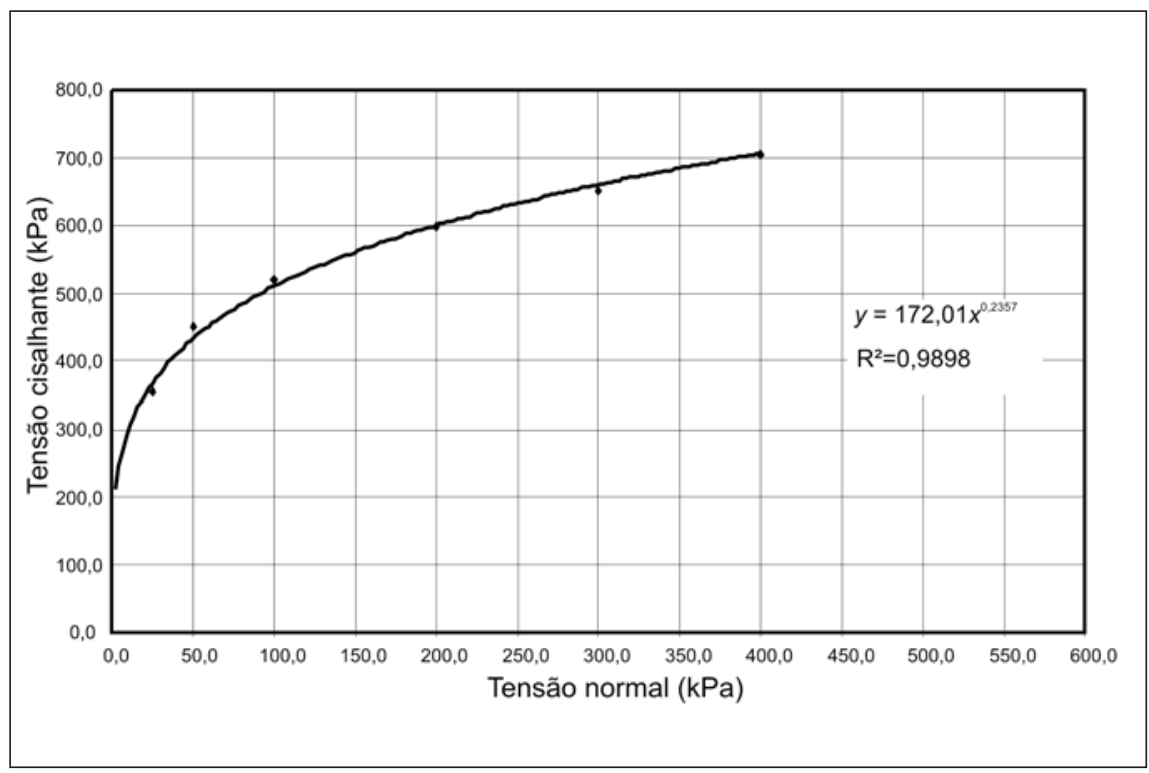

Figura 2 - Envoltória de resistência da Cava Crista. 
se encontra próximo ao obtido nas amostras da Cava Cachorro Bravo, por meio do ensaio de cisalhamento direto.

Cabe salientar que não foi possível obter os parâmetros de resistência para os blocos das Cavas Cachorro Bravo e Crista após a ciclagem, devido à perda de várias amostras durante o ensaio de alterabilidade.

\section{Considerações finais}

É importante ressaltar que esse trabalho vem contribuir na geração de dados a respeito da caracterização de rochas brandas na região do Quadrilátero Ferrífero. A adoção de uma metodologia aplicável a solos nas rochas alteradas, como no caso do ensaio de cisalhamento direto, mostrou-se satisfatória.

A variação nos índices físicos com o ensaio de alterabilidade, porosidade, índice de vazios (aumento), peso específico seco (redução) constitui importante indicador do processo de alteração sofrido pelas rochas, o que, conseqüentemente, interfere na resistência do maciço rochoso, com a rocha degradando pela ação da água que penetra por suas aberturas. Também a queda de coesão das amostras da Cava Cristina, após o ensaio de alterabilidade, mostra a importância do processo de alteração na redução da resistência ao cisalhamento da superfície de xistosidade. Deve-se ressaltar que não foram encontrados, na literatura, dados de queda de resistência ao cisalhamento com o ensaio de alterabilidade, provavelmente pela sua dificuldade de obtenção.

A superfície de crenulação, presente nas amostras ensaiadas da Cava Crista, contribui para o aumento da resistência ao cisalhamento na superfície de xistosidade. Observa-se um padrão distinto com relação às áreas estudadas, enquanto que, na Cava Crista, verifica-se considerável estabilidade nos taludes. Na área da Cava Cachorro Bravo, o maciço é mais alterado que o da Cava Crista e os taludes apresentam rupturas de porte considerável.
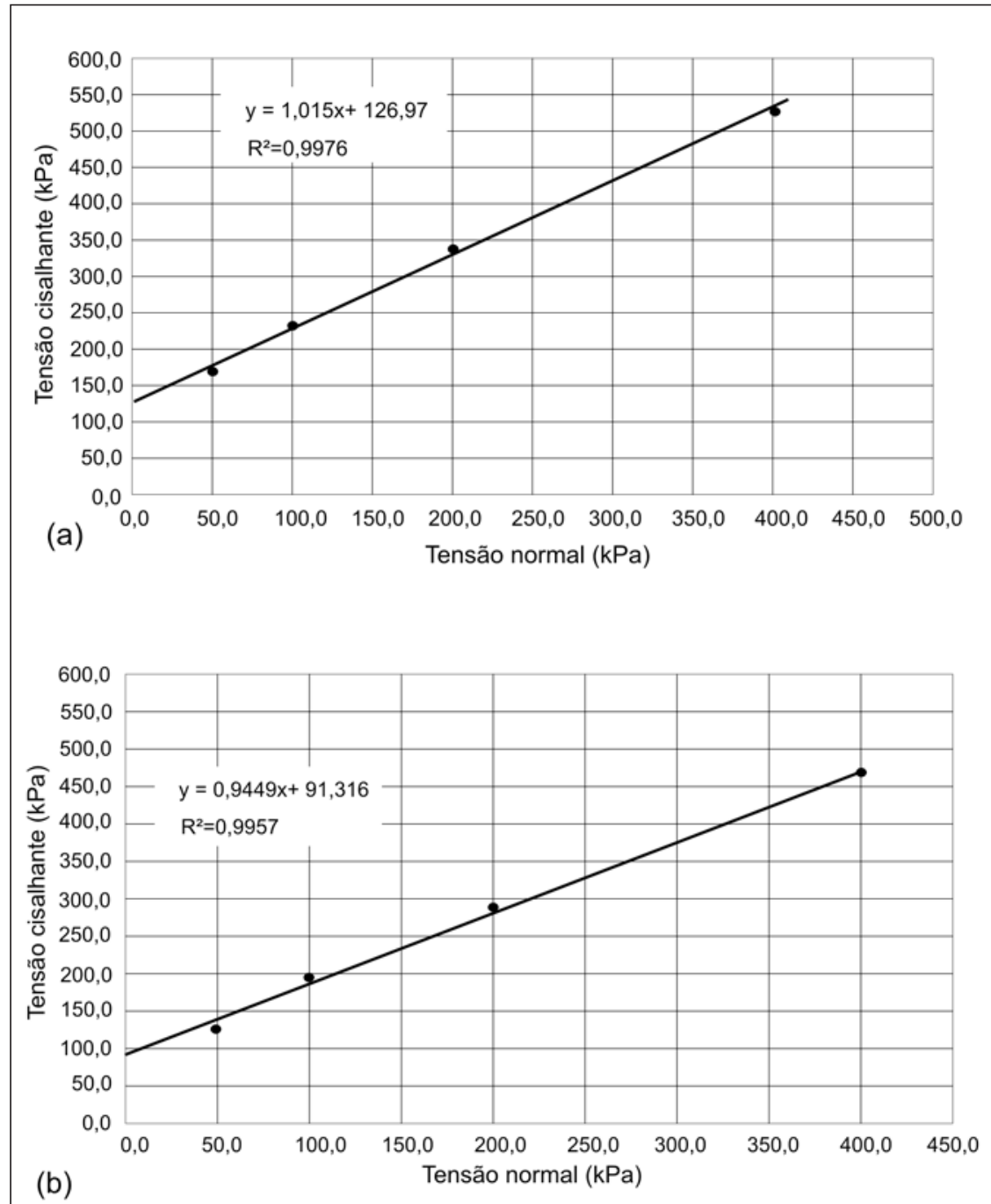

Figura 3 - Envoltória de resistência da Cava Cristina: (a) sem ciclagem e (b) após ensaio de alterabilidade.

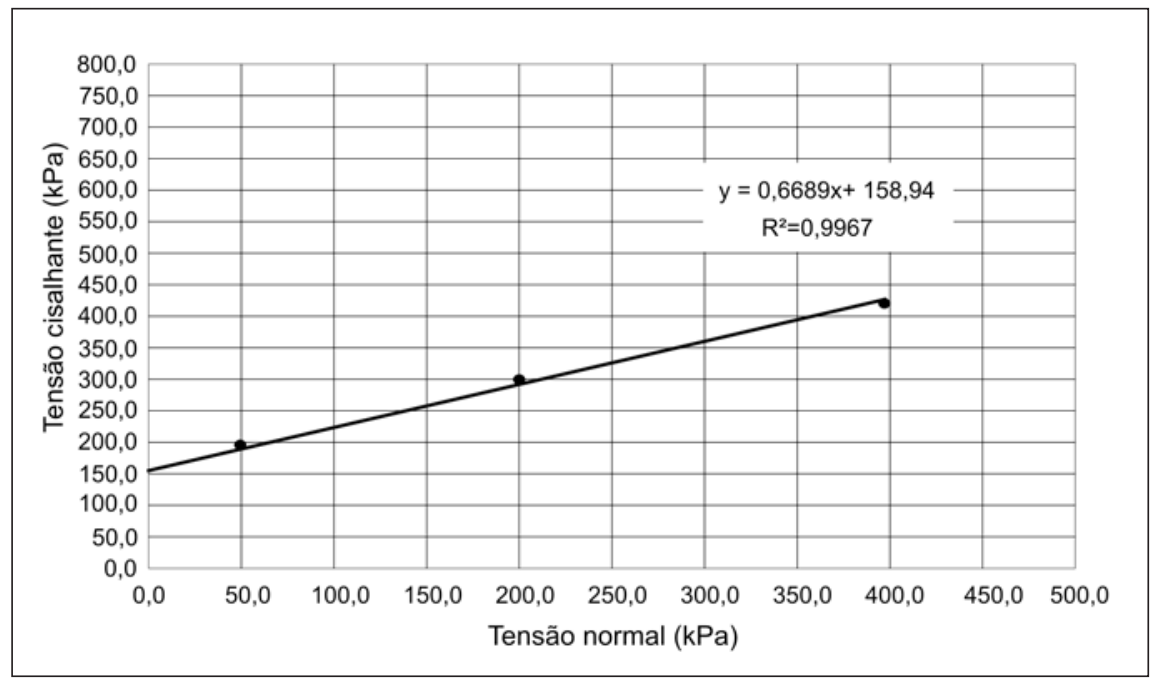

Figura 4 - Envoltória de resistência para a Cava Cachorro Bravo. 


\section{Referências}

\section{bibliográficas}

ABNT NBR 6508. Grãos que passam na \# 4,8mm, determinação da massa específica. 1984. 8p.

CENTRAIS ELÉTRICAS DE SÃO PAULO-CESP MRL-02. Ensaio de alteração em rocha-ciclagem águaestufa. Laboratório Central de Engenharia Civil/CESP,1990.10p.

FERNANDES, G. Caracterização geológicogeotécnica e proposta de estabilização da encosta do Morro do Curral. Ouro Preto: Centro de Artes e Convenções de Ouro Preto - UFOP, 2000. 136p. (Dissertação de Mestrado).
FERREIRA,S.B.Estudo de ruptura em talude urbano no Morro do Curral. Universidade Federal de Ouro Preto,2004. 87p. (Dissertação de Mestrado).

FIGUEIREDO, R.P., AQUINO, T.V.C. Caracterização e retro-análise preliminar do mecanismo de tombamento flexural-Mina do Pico/MBR. In: CONGRESSO DE GEOLOGIADE ENGENHARIA E AMBIENTAL, 11. Anais... Florianópolis, 2005. p.2274-2290.

ISRM. Rock Characterization Testing and Monitoring. 1981. 211p.

MARQUES,E.A.G.,VARGAS JR,E.A. Weatherability and alteration studies of some shales and siltstones from the Recôncavo sedimentary basin. In: INTERNATIONAL IAEG CONGRESS, 7. Rotterdam. 1994. p.729-738.

WATTERS,R.J. The effects of weathering on rock masses. In: Characterization of Weak and Weathered Rock Masses. Portland: Association of Engineering Geologists- Annual Meeting, 1997. p.37-52.

Artigo recebido em 04/07/2006 e aprovado em 16/02/2007.

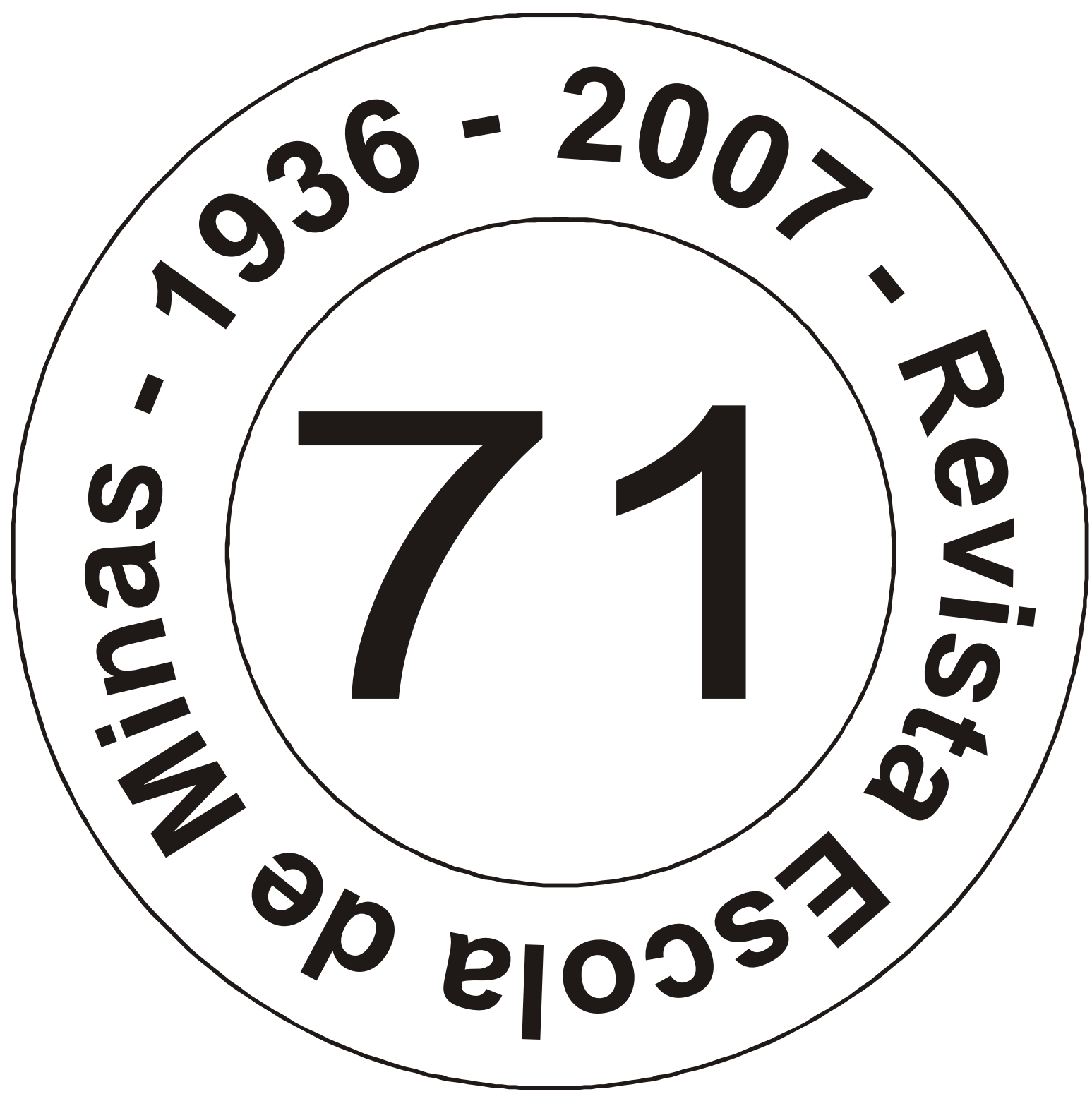

